\title{
PENINGKATAN KEMAMPUAN GURU SD DI WILAYAH BINAAN KOTA TASIKMALAYA DALAM MENULIS PROPOSAL PENELITIAN TINDAKAN KELAS (PTK) MELALUI BIMBINGAN TERSTRUKTUR
}

\author{
Elah Hayati \\ Dinas Pendidikan Kota Tasikmalaya, JL. Ir. H. Juanda, Tasikmalaya, Indonesia \\ Email: haryatiii1201@gmail.com
}

\begin{abstract}
The task of a teacher not only provides the students a learning process, but also runs their professional demand on making efforts to correct deficiencies in carrying out their duties. Empirically, teachers who are experienced in teaching have unconsciously carried out a number of additional activities that are not included in the lesson plan unit, namely, Classroom Action Research. Thus, scientific research and writing is a teacher's professional development at which a teacher can carry out classroom action research which is called teacher scientific activities. It is conducted by developing innovations in learning such as using methods and media strategies to improve their professional competence. Therefore, the aim of this research is to find out whether or not structured guidance can improve the ability of elementary school teachers in the target areas of Kota Tasikmalaya in overcoming difficulties in preparing CAR and its implementation in the classroom. The method used in this research is descriptive qualitative method with the type of School Action Research (PTS) approach. This research was conducted at SD Negeri 1 Purbaratu. in the second semester of the 2018/2019 academic year, precisely in August-October 2018. Based on the results of the research obtained from processed and analysed data that have been carried out, it can be concluded that the application of structured guidance can improve the ability of elementary school teachers in the target areas of Tasikmalaya City to carry out Classroom Action Research. This can be seen from the indicators of success which is shown by an increase from successful to very successful regarding the formulation of the CAR title; and from less successful to moderately successful dealing with the Classroom Action Research Report.
\end{abstract}

Keywords: Writing CAR, Structured Guidance

Tugas seorang guru tidak hanya memberikan pembelajaran bagi para peserta didiknya, tapi guru harus mampu menjalankan tuntutan profesinya untuk melakukan upaya perbaikan atas kekurangan-kekuranganya dalam melaksanakan tugasnya. Secara empiris, guru yang berpengalaman mengajar secara tidak sadar telah melakukan sejumlah kegiatan tambahan yang tidak tercantum dalam satuan pelajaran, yakni, sebenarnya, ia telah melaksanakan Penelitian Tindakan Kelas. Dengan demikian, penelitian dan karya tulis ilmiah merupakan pengembangan profesi guru dimana seorang guru dapat melakukan penelitian tindakan kelas yang disebut dengan kegiatan ilmiah guru. Kegiatan ini berupa pengembangan inovasi dalam pembelajaran seperti penggunaan metode dan strategi media demi meningkatkan kompetensi profesionalnya. Oleh sebab itu, tujuan dari penelitian ini adalah untuk mengetahui apakah bimbingan terstruktur dapat meningkatkan kemampuan guru SD wilayah binaan Kota Tasikmalaya dalam mengatasi kesulitan menyusun PTK dan pelaksanaannya di kelas. Metode yang digunakan dalam penelitian ini adalah metode deskriptif kualitatif dengan pendekatan Penelitian Tindakan Sekolah (PTS). Penelitian ini dilaksanakan di SD Negeri 1 Purbaratu pada semester II tahun Pelajaran 2018/2019 tepatnya pada bulan Agustus- Oktober 2018. Berdasarkan hasil penelitian, pengolahan data dan analisis yang telah dilakukan, dapat disimpulkan bahwa penerapan bimbingan terstruktur dapat meningkatkan kemampuan guru-guru SD di wilayah binaan Kota Tasikmalaya dalam melaksanakan Penelitian Tindakan Kelas, hal ini terlihat dari indikator keberhasilan yang menunjukkan adanya peningkatan dari berhasil ke sangat berhasil untuk perumusan judul PTK; dan dari kurang berhasil ke cukup berhasil untuk Laporan Penelitian Tindakan Kelas.

Kata Kunci: Penulisan PTK, Bimbingan Terstruktur

Cara sitasi: Hayati, E. (2021). Peningkatan Kemampuan Guru SD di Wilayah Binaan Kota Tasikmalaya dalam Menulis Proposal Penelitian Tindakan Kelas (PTK) Melalui Bimbingan Terstruktur. J-KIP (Jurnal Keguruan dan IImu Pendidikan), 2 (1), 39-44. 


\section{PENDAHULUAN}

Tugas seorang guru bukanlah hanya sekedar memberikan pembelajaran bagi para peserta didiknya. Seorang guru mempunyai empat kompetensi yaitu kompetensi pedagogik, kepribadian, professional dan sosial. Menurut Undang-undang No. 14 tahun 2005 tentang Guru dan Dosen, kompetensi profesional adalah "kemampuan penguasaan materi pelajaran secara luas dan mendalam". Kompetensi profesional merupakan kemampuan yang diperlukan agar dapat mewujudkan dirinya sebagai guru profesional.

Kompetensi profesional meliputi kepakaran atau keahlian dalam bidangnya yaitu penguasaan bahan yang harus diajarkannya beserta metodenya, rasa tanggung jawab akan tugasnya dan rasa kebersamaan dengan sejawat guru lainnya. Arti dari profesional adalah sebuah profesi yang tidak dapat dilakukan oleh sembarangan orang (Usman dan Asnawir, 2006). Guru yang profesional akan mampu menciptakan perubahan-perubahan mutu pendidikan yang sangat mendasar. Dan perubahan itu akan sangat tergantung kepada apa yang guru lakukan dan guru pikirkan tentang pendidikan.

Guru merupakan kunci keberhasilan pendidikan dan keberhasilannya tercermin dalam hasil belajar siswa. Hasil belajar merupakan gambaran tentang bagaimana siswa memahami materi yang disampaikan oleh guru (Tari, et. al. 202). Dengan tugas profesional dan didukung oleh kompetensi pedagogiknya, guru berfungsi membantu orang lain (peserta didik) untuk belajar dan berkembang, membantu perkembangan intelektual, personal dan social warga masyarakat yang memasuki sekolah. Guru harus memperhatikan dan memahami suasana kelas dan menangani kelas secara sejuk, tidak meledak- ledak.

Tugas utama guru, selain mendidik adalah mengajar sebagai pengajar, guru dihadapkan pada tuntutan profesi untuk melakukan upaya perbaikan atas kekurangan-kekurangan dalam melaksanakan tugasnya. Secara empiris, guru yang berpengalaman mengajar secara tidak disadari telah melakukan sejumlah kegiatan tambahan yang tidak tercantum dalam satuan pelajaran tetapi ia telah melaksanakan Penelitian Tindakan Kelas.

Saat ini penelitian tindakan kelas (PTK) memang mendapatkan perhatian yang cukup besar dalam dunia pendidikan. PTK bahkan merupakan ikon khusus dari program pemerintah dalam upaya peningkatan kualitas guru dan tenaga kependidikan pada umumnya. Pemerintah juga secara khusus setiap tahun memberikan dana bagi guru yang mampu merencanakan dan melakukan PTK dengan baik (Depdiknas, 2008). PTK menjadi semakin mendapatkan prioritas untuk bisa dilakukan guru, mengingat adanya manfaat ganda dari PTK. Santyasa (2007) yang menyatakan bahwa PTK sangat mendukung program peningkatan kualitas pembelajaran di sekolah, yang muaranya adalah peningkatan kualitas pendidikan PTK disamping memberikan manfaat bagi peningkatan kualitas pembelajaran/ pendidikan, laporan PTK juga sangat bermanfaat bagi guru yang bersangkutan dalam hal kenaikan pangkat dan kredit pengembangan profesi keguruan.

Guru sebagai peneliti agar dapat melaksanakan PTK dengan baik perlu menyusun rencana penelitian dalam bentuk proposal PTK. Kenyataan di sekolah menunjukkan bahwa masih banyak guru yang kurang memahami PTK dan mengalami kesulitan dalam menyusun proposal PTK. Keadaan seperti ini juga terjadi pada guru-guru SD di wilayah binaan kota Tasikmalaya. Hasil wawancara penulis dengan kepala sekolah SD di wilayah binaan Kota Tasikmalaya menunjukkan bahwa banyak guru yang mengalami kesulitan dalam menyusun proposal PTK dan melaksanakannya di kelas sehingga perlu adanya bimbingan khusus.

Martono (2010) menyatakan bahwa metode tutorial yang diterapkan pada proses pembelajaran Diklat PTK dapat mengoptimalkan kemampuan guru- guru dalam menyusun proposal PTK. Oleh sebab itu masalah penelitian ini dapat dirumuskan sebagai berikut " Apakah bimbingan terstruktur dapat meningkatkan kemampuan guru SD di wilayah binaan Kota Tasikmalaya dalam menulis Penelitian Tindakan Kelas?". 


\section{METODE PENELITIAN}

Subjek penelitian tindakan sekolah ini adalah 30 orang guru SD yang merupakan perwakilan dari masing- masing Sekolah Dasar yang berada di wilayah binaan Kota Tasikmalaya yang mencakup 10 Sekolah Dasar yang terdiri dari: SD Negeri 1 Purbaratu, SD Negeri 2 Purbaratu, SD Negeri 4 Purbaratu, SD Negeri Singkup, SD Negeri 1 Karangsambung, SD Negeri 2 Karangsambung, SD Negeri 3 Karangsambung, SD Negeri 4 Karangsambung, SD Negeri Cibangunkidul dan SD Negeri Margamulya. Penelitian ini dilaksanakan pada semester II tahun Pelajaran 2018/2019 tepatnya pada bulan Agustus- Oktober 2018. Penelitian ini dilaksanakan di SD Negeri 1 Purbaratu yang beralamat di Jalan Subanagara No.4, Purbaratu, Tasikmalaya, Jawa Barat 46196 Kota Tasikmalaya Prov. Jawa Barat.

Penelitian direncanakan dalam 2 kali siklus penelitian, masing-masing siklus terdiri dari 4 tahapan kegiatan yaitu perencanaan, pelaksanaan tindakan, pengamatan dan refleksi. Kegiatan Penelitian tindakan sekolah meliputi:

\section{Perencanaan}

Langkah langkah dalam melakukan perencanaan antara lain:

a. Melakukan identifikasi masalah dan penetapan alternatif pemecahan masalah.

b. Merencanakan penelitian dengan membuat proposal penelitian dan supervisi akademik.

c. Menetapkan tindakan yang akan dilakukan dalam kegiatan penelitian.

d. Mengembangkan instrumen penelitian untuk mengetahui input, proses dan output penelitian dan supervisi akademik. Instrumen yang digunakan terdiri:

1) Lembar pengamatan instruktur (observing instrukture).

2) Instrumen untuk mengamati kelas (observing classroom), dengan menggunakan observasi kelas terstruktur (Structured Observation of Classrooms).

3) Instrumen untuk mengamati perilaku peserta (observing) malalui catatan anekdotal perilaku peserta (Anecdotal Record for Observing Teacher).

Untuk memperoleh data dan atau informasi yang lebih rinci dan untuk melengkapi data hasil observasi, peneliti melakukan wawancara kepada instruktur dan, peserta. Wawancara digunakan untuk mengungkap data yang berkaitan dengan sikap, pendapat, atau wawasan. pedoman pengkajian data dokumen berupa: daftar hadir, perangkat pembelajaran, quesioner dan hasil pengamatan mengajar.

\section{Pelaksanaan Tindakan}

Tindakan yang dilakukan peneliti dalam kegiatan pelaksanaan tindakan meliputi pelaksanaan bimbingan dalam pembuatan PTK.

\section{Pengamatan}

a. Melakukan observasi dengan memakai format observasi yang sudah disiapkan yaitu dengan catatan anekdot.

b. Mengumpulkan lembar hasil penilaian preetes dan post tes, lembar quesioner serta catatan anekdot hasil diskusi.

c. Mengolah data hasil tes dan diskusi.

d. Menilai hasil kegiatan bimbingan tersturktur dalam melakukan penulisan PTK.

\section{Refleksi}

a. Melakukan evaluasi tindakan yang telah dilakukan meliputi evaluasi penyelenggaraan (instruktur, situasi kelas dan peserta pelatihan) dari segi mutu, jumlah dan waktu dari setiap macam tindakan.

b. Melakukan pertemuan untuk membahas hasil evalusi tentang penulisan PTK.

c. Memperbaiki pelaksanaan tindakan sesuai hasil evaluasi, untuk digunakan pada siklus berikutnya. 


\section{HASIL DAN PEMBAHASAN}

Hasil penelitian dalam Penelitian Tindakan Sekolah ini diuraikan sebagai berikut : 1) Pada awal bimbingan guru-guru Matematika belum ada yang membuat laporan PTK, hal ini dikarenakan belum memahami cara membuat laporan PTK, kesulitan dalam mencari sumber untuk kajian teori, tak memiliki perangkat komputer sendiri di rumah, dan masih bingungnya guru-guru tersebut tentang bagaimana cara melaksanakan PTK meskipun telah mendapatkan informasi tentang PTK, 2) Hasil penelitian tindakan dengan menerapkan bimbingan terstruktur menunjukkan adanya peningkatan pemahaman baik merumuskan judul PTK maupun membuat laporan PTK untuk setiap siklusnya mulai dari siklus I sampai siklus II, baik kegiatan merumuskan judul PTK, maupun pembuatan laporan PTK seperti terlihat pada Tabel 1.

Tabel 1. Nilai Rata-Rata Perumusan Judul PTK

\begin{tabular}{cc}
\hline Tindakan & Rata- Rata Perolehan Skor \\
\hline Siklus I & 46,17 \\
Siklus II & 83,33 \\
\hline
\end{tabular}

Berdasarkan Tabel 1 dilihat dari nilai rata-rata masing-masing siklus terjadi peningkatan yang signifikan dari pelaksanaan siklus I ke siklus II. Siklus I skor rata-rata adalah 46,17, sedangkan siklus II skor rata-rata adalah 83,33 , jadi terjadi kenaikan sekitar $37,16 \%$ dari skor ideal. Hal ini menunjukan bahwa tindakan yang dilakukan oleh peneliti dalam membimbing guru SD di wilayah binaan Kota Tasikmalaya sudah tepat. Hal ini ditandai dengan membuat perencanaan dan pelaksanaan siklus II yang sesuai dengan hasil refleksi dari siklus I.

Gambar 1 adalah diagram yang menunjukkan adanya peningkatan skor rata-rata perumusan judul PTK guru SD di wilayah binaan Kota Tasikmalaya.

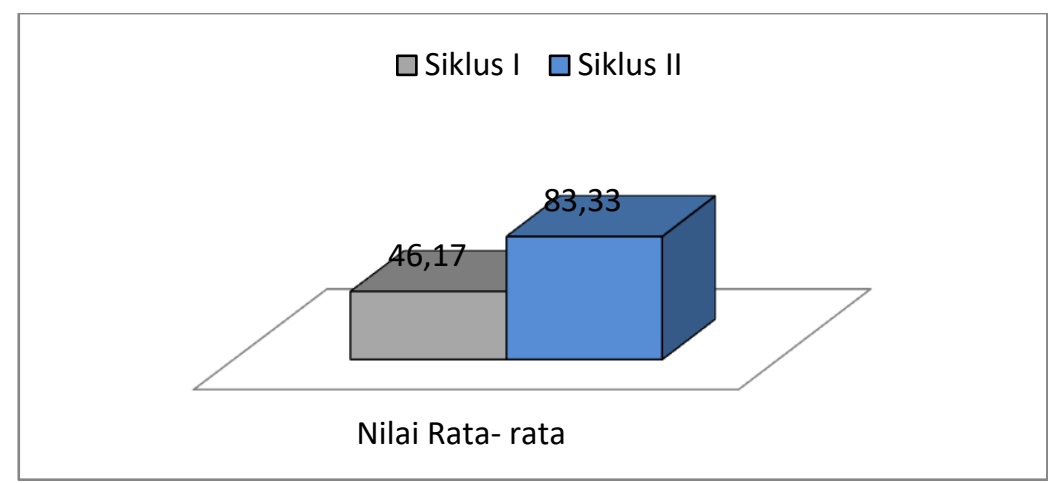

\section{Gambar 1. Nilai Rata-Rata Perumusan Judul PTK}

Selanjutnya peningkatan terjadi pada penyusunan laporan PTK, selanjutnya peningkatan terjadi pada penyusunan laporan PTK, hal ini nampak dari skor rata-rata laporan PTK pada masingmasing siklus seperti Tabel 2.

Tabel 2. Nilai Rata-Rata Laporan PTK

\begin{tabular}{cc}
\hline Tindakan & Rata- Rata Perolehan Skor \\
\hline Siklus I & 55,50 \\
Siklus II & 84,83 \\
\hline
\end{tabular}

Berdasarkan Tabel 2 terjadi peningkatan skor rata-rata penyusunan laporan PTK dari 55,50 skor rata-rata siklus I ke 84,83 skor rata-rata siklus II sekitar 29,33 dari skor ideal. Hal ini menunjukan bahwa guru SD di wilayah binaan Kota Tasikmalaya memiliki kemampuan belajar yang baik dalam memperbaiki kesalahan pada penyusunan laporan PTK. 
Gambar 2 adalah diagram yang menunjukkan adanya peningkatan skor rata-rata penyusunan laporan PTK guru SD di wilayah binaan Kota Tasikmalaya.

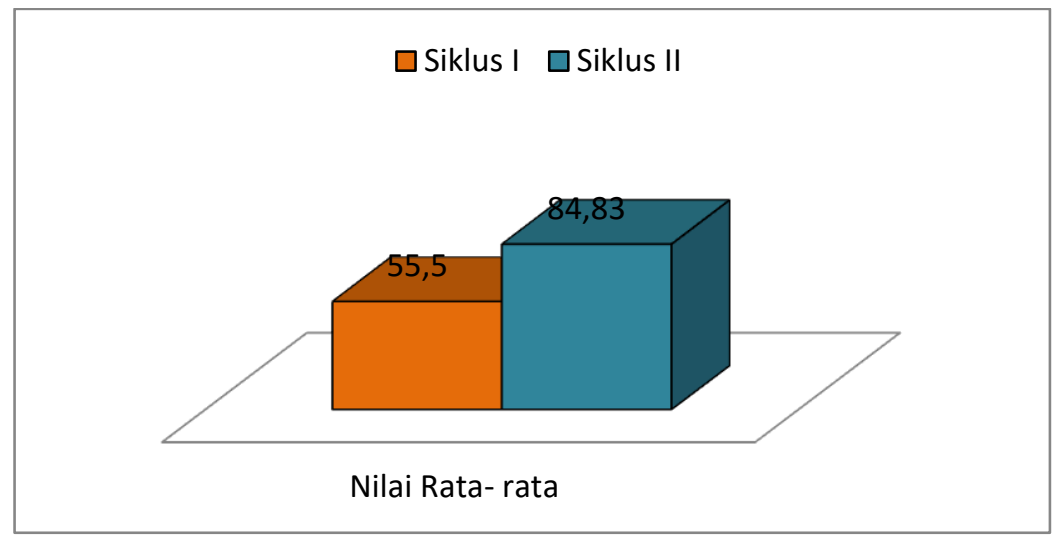

Gambar 2. Nilai Rata-Rata Laporan PTK

Berdasarkan paparan tersebut PTK adalah kegiatan yang dipicu oleh permasalahan praktis yang dihayati dalam pelaksanaan tugas sehari hari oleh guru sebagai pengelola program pembelajaran di kelas. PTK diselenggarakan secara kolaboratif antara guru yang kelasnya dijadikan kancah PTK dengan dosen LPTK. Keterlibatan dosen LPTK bukanlah sebagai ahli pendidikan yang tengah mengemban fungsi sebagai Pembina guru atau sebagai pengembang pendidikan melainkan senagai sejawat, disamping sebagai pendidik calon guru yang seyogyanya memiliki kebutuhan untuk belajar dalam rangka mengakrabi lapangan demi peningkatan mutu kinerjanya sendiri. Rohani (2004) mengungkapkan bahwa Pembinaan guru adalah serangkaian bantuan yang berwujud layanan profesional yang diberikan oleh orang yang lebih ahli (kepala sekolah, pengawas, ahli lainnya) kepada guru dengan maksud agar dapat meningkatkan kualitas proses dan hasil belajar, sehingga tujuan pendidikan yang direncanakan dapat tercapai.

Hasil penelitian ini mudah-mudahan dapat meningkatkan kompetensi profesional, yaitu kemampuan penguasaan materi pembelajaran secara luas dan mendalam yang memungkinkannya membimbing peserta didik memenuhi standar kompetensi. Salah satu mencakupkan kompetensinya adalah meningkatkan kualitas pembelajaran melalui Penelitian Tindakan Kelas. Melalui pendampingan intensif dari pelatih, guru- guru berani mencoba dan tidak takut salah dalam menyusun proposal PTK, sehingga guru-guru dapat menghasilkan proposal PTK (Evanelda, 2018).

\section{KESIMPULAN}

Berdasarkan hasil penelitian, pengolahan data dan analisis yang telah dilakukan dalam penelitian ini, maka dapat disimpulkan bahwa penerapan bimbingan terstruktur dapat meningkatkan kemampuan guru-guru SD di wilayah binaan Kota Tasikmalaya dalam melaksanakan Penelitian Tindakan Kelas, hal ini terlihat dari indikator keberhasilan yang menunjukkan adanya peningkatan dari berhasil ke sangat berhasil untuk perumusan judul PTK dan dari kurang berhasil ke cukup berhasil untuk Laporan Penelitian Tindakan Kelas.

Adapun saran yang dapat penulis sampaikan adalah sebagai berikut: 1) Kepala sekolah menggunakan metoda bimbingan terstruktur sebagai salah satu solusi ketika membimbing guru melaksanakan PTK; serta agar terus mendorong dan memotivasi guru-guru untuk melaksanakan PTK baik dalam bentuk materi maupun non materi; 2) Guru SD di wilayah binaan Kota Tasikmalaya perlu mengembangkan Penelitian Tindakan Kelas untuk memperbaiki proses pembelajaran, dan 3) Guru secara umum perlu terus-menerus membaca literatur baik dari buku-buku maupun internet. 


\section{REKOMENDASI}

Rekomendasi dari penelitian ini adalah waktu melakukan pembimbingan hendaknya dicari waktu yang luang dan pertemuan yang teratur supaya proses pembimbingan berjalan lebih baik.

\section{UCAPAN TERIMAKASIH}

Penulis mengucapkan terima kasih kepada 30 orang guru SD yang telah mendukung terhadap pelaksanaan penelitian ini.

\section{DAFTAR PUSTAKA}

Depdiknas. (2008). Peraturan Pemerintah RI No.19 Tahun 2005 tentang Standar Nasional Pendidikan. Jakarta: Depdiknas.

Evanelda. (2018). Peningkatan Kemampuan Guru Dalam Menyusun Proposal Penelitian Tindakan Kelas Melalui Model Pembinaan Clck (Contoh, Latihan, Control, Kerja Mandiri) Berbasis Pendampingan Intensif Di SDN 17 Simaung Cumateh. Jurnal Manajemen Pendidikan, 3(3): $421-431$.

Martono, N. (2010). Metode Penelitian Kuantitatif. Jakarta: PT Raya Grafindo Persada.

Rohani, N. K. (2004). Pengaruh Pembinaan Kepala Sekolah dan Kompensasi Terhadap Kinerja Guru SLTP Negeri di Kota Surabaya. Jurnal Pendidikan Dasar, 5 (1), 71- 78.

Santyasa, I. W. (2007). Metodologi Penelitian Tindakan Kelas (makalah disampaikan dalam Pendidikan dan Pelatihan Metodologi Penelitian, Penyusunan Proposal, dan Penulisan Karya IImiah bagi Guru-Guru SMP dan SMA/SMK di Kabupaten Buleleng pada Tanggal 10-16 September 2007 di Universitas Pendidikan Ganesha Singaraja).

Tari, H. D ., Suwirta, U \& Dedeh. (2020). Pengaruh Penerapan Model Pembelajaran Kooperatif Tipe Teams Games Tournament (TGT) terhadap Hasil Belajar Peserta Didik pada Mata Pelajaran Ekonomi di MAN 2 Kota Tasikmalaya. J-KIP (Jurnal Keguruan dan IImu Pendidikan), 1 (2), 19-26.

Usman, M. B., \& Asnawir. (2002). Media Pembelajaran. Jakarta: Ciputat Press. 